\title{
PEMANFAATAN KARBON AKTIF DARI BAMBU SEBAGAI ELEKTRODA SUPERKAPASITOR
}

\author{
Farly Tumimomor ${ }^{1)}$, Akhiruddin Maddu ${ }^{2)}$, Gustan Pari ${ }^{3)}$ \\ ${ }^{1)}$ Jurusan Fisika FMIPA Universitas Negeri Manado \\ ${ }^{2)}$ Departemen Fisika, FMIPA, Institut Pertanian Bogor \\ ${ }^{3)}$ Pusat Penelitian dan Pengembangan Keteknikan Kehutanan dan Pengolahan Hasil Hutan Bogor \\ e-mail : reynol.tumimomor@yahoo.com; akhiruddin@ipb.ac.id; gustanp@yahoo.com
}

\begin{abstract}
ABSTRAK
Pada penelitian ini, karbon aktif berbasis bambu telah digunakan untuk pembuatan superkapasitor. Uji daya jerap iodin dilakukan untuk mengukur tingkat serapan pori sampel karbon aktif yang ukurannya relatif kecil (mikropori). Karakteristik bahan karbon aktif yang meliputi struktur kristal dan morfologi permukaannya diuji dengan menggunakan SEM dan XRD. Bahan elektroda dengan komposisi (Karbon aktif : PVDF = 9:1 (b/b)), kolektor arus dan separator telah dirangkai untuk diuji kinerjanya sebagai perangkat penyimpanan muatan listrik. Metode siklik voltametri digunakan untuk melihat kinerja perangkat superkapasitor dengan mengukur nilai kapasitansi spesifik berdasarkan kurva voltammogram. Berdasarkan hasil perhitungan nilai kapasitansi spesifik diperoleh nilai kapasitansi spesifik tertinggi pada superkapasitor dengan elektroda bambu yang diaktivasi dengan steam $50 \mathrm{~mL} /$ bar yaitu sebesar $59.50 \mathrm{~F}$.
\end{abstract}

Kata kunci: Karbon aktif bambu, siklik voltametri, kapasitansi spesifik, superkapasitor.

\section{UTILIZATION OF BAMBOO BASED ACTIVATED CARBON AS SUPERCAPACITOR ELECTRODE}

\begin{abstract}
In this study, bamboo based activated carbon has been used for fabrication of supercapacitors. Iodine absorption test is performed to measured absorption level porous activated carbon sample size is relatively small (microporous). Characteristics of the activated carbon material covering the surface morphology and structure were tested using SEM and XRD. Electrode materials with composition (Activated charcoal: PVDF = 9: $1(\mathrm{w} / \mathrm{w})$ ), the current collector and separator has been assembled to be tested its performance as an electrical charge storage device. The test results by cyclic voltammetry method was to look at the performance supercapacitor devices at once to obtain the value of the capacitance curve obtained voltammograms. Based on the results of the calculation of the capacitance, the highest capacitance values obtained in the supercapacitor with activated carbon electrodes in bamboo steam $50 \mathrm{~mL} /$ bar with a capacitance value is $59.50 \mathrm{~F} / \mathrm{g}$.
\end{abstract}

Keywords: Bamboo activated carbon, cyclic voltammetry, the specific capacitance, supercapacitor.

\section{PENDAHULUAN}

Penyediaan energi di masa depan merupakan permasalahan yang senantiasa menjadi perhatian semua bangsa karena bagaimanapun juga kesejahteraan manusia dalam kehidupan modern sangat terkait dengan jumlah dan mutu energi yang dimanfaatkan. Bagi Indonesia yang merupakan salah satu negara sedang berkembang, penyediaan energi khususnya energi listrik merupakan faktor yang sangat penting dalam mendorong pembangunan. Menurut (La Ode Muhammad 2005) pemakaian energi listrik selama kurun waktu tahun 2000 sampai dengan tahun 2025 diperkirakan meningkat rata-rata $7,1 \%$ per tahun.

Energi listrik dapat dihasilkan dari sumber energi terbarukan seperti, matahari dan angin, akan tetapi efektivitas penggunaannya membutuhkan penyimpanan energi listrik yang efisien. Pengembangan dalam sistem penyimpanan energi listrik 
sangat penting untuk penyamarataan efektivitas alami siklus sumber-sumber energi (Chijuan Hu 2008).

Baterai dan superkapasitor adalah teknologi sistem penyimpanan energi listrik terkemuka saat ini. Keduanya didasarkan pada mekanisme elektrokimia. Baterai menyimpan energi listrik dalam senyawa kimia yang mampu menghasilkan muatan, sedangkan superkapasitor menyimpan energi listrik secara langsung sebagai muatan. (Yueming Li et al. 2011) mengemukakan bahwa dalam beberapa tahun terakhir, superkapasitor sangat menarik perhatian dalam teknologi penyimpanan energi listrik karena memiliki kerapatan energi yang lebih tinggi dibandingkan kapasitor konvensional dan kerapatan daya yang lebih tinggi dibandingkan baterai. Keuntungan lain dari superkapasitor adalah tingkat pengisian yang cepat dan umur siklus pengisian yang panjang (Zuleta 2005).

Salah satu faktor yang mempengaruhi tingkat keefektifan superkapasitor adalah penggunaan bahan elektroda. Karbon aktif adalah salah satu jenis bahan yang secara luas telah digunakan sebagai bahan elektroda untuk superkapasitor karena memiliki luas permukaan spesifik yang tinggi, ketahanan kimia, konduktivitas listrik yang baik dan harga yang terjangkau (Babel dan Jurewicz 2004; Fellman 2010; Aripin et al. 2010). Bambu dapat dijadikan sumber bahan baku dalam pembuatan karbon aktif. Kandungan karbon dalam lignin dan selulosa yang terdapat pada bambu, menjadikan bahan ini dapat dijadikan alternatif dalam pembuatan karbon aktif.

Pada penelitian ini, telah dibuat dan dikarakterisasi superkapasitor menggunakan bahan karbon aktif berbasis bambu sebagai elektroda dengan aktivator $\mathrm{KOH}$ dan variasi laju aliran uap air dalam proses aktivasi untuk menghasilkan perangkat superkapasitor sebagai perangkat penyimpanan energi listrik dan pada akhirnya menghasilkan teknologi sistem penyimpanan energi listrik yang ekonomis.

\section{METODE PENELITIAN}

\section{Bahan}

Bahan yang digunakan dalam penelitian ini adalah arang bambu, $\mathrm{KOH}, \mathrm{HCl} 10 \%$, akuades, $\mathrm{pH}$ indikator, PVDF 10\%, larutan
NMP, larutan elektrolit $\mathrm{H}_{2} \mathrm{SO}_{4} 1 \mathrm{M}$, larutan $\mathrm{AgNO}_{3} \quad 0,1 \mathrm{M}$, membran PTFE, plastik acrylic, stainless stell 100 mesh.

\section{Metode}

1. Proses aktivasi bambu

Tahap pertama adalah pembentukan arang bambu melalui proses karbonisasi pada suhu $400^{\circ} \mathrm{C}$ selama 4 jam, selanjutnya mencampur $\mathrm{KOH}$ dan arang dengan perbandingan massa 3:1. Campuran ini dibiarkan selama 24 jam untuk menjamin keberlangsungan proses difusi ke bagian dalam pori arang. Tahap selanjutnya campuran dijemur sampai kering. Serbuk arang yang sudah dicampur tersebut diaktivasi pada suhu $800^{\circ}$ selama 60 menit (Aripin et al.. 2010) dengan variasi laju uap air (steam) $25 \mathrm{~mL} / \mathrm{bar}$ dan $50 \mathrm{~mL} / \mathrm{bar}$. Tahap terakhir adalah pencucian arang dengan $\mathrm{HCl}$ dan aquades untuk membuang senyawa garam alkali. Karbon aktif selanjutnya dikeringkan pada suhu $100^{\circ} \mathrm{C}$ selama 24 jam untuk mengeluarkan uap air yang terjebak di dalam pori.

2. Uji daya jerap iodin

Karbon aktif ditimbang sebanyak 0,25 gram, kemudian dilarutkan dalam $25 \mathrm{~mL}$ larutan iodin 0,1 $\mathrm{N}$ dalam labu Erlenmeyer. Labu Erlenmeyer tersebut selanjutnya digoyang selama 15 menit, kemudian disaring dengan kertas saring. Larutan iodin hasil saringan tersebut diambil sebanyak 10 $\mathrm{mL}$ dititrasi dengan larutan $\mathrm{Na}_{2} \mathrm{~S}_{2} \mathrm{O}_{3} 0,1 \mathrm{~N}$ sampai warna larutan menjadi bening. Perlakuan titrasi tersebut dilakukan sebanyak 2 kali (duplo).

3. Uji konduktivitas

Karbon aktif ditimbang sebanyak 0,3 gram, kemudian dimasukkan ke dalam tabung silinder berdiameter $1,51 \mathrm{~cm}$ dan panjang $\pm 10 \mathrm{~cm}$. Karbon aktif yang telah dimasukkan dalam tabung ditutup dengan cara ditekan dengan penutup tabung hingga tertutup rapat. Setelah itu tabung silinder yang telah berisi arang tersebut diuji konduktivitasnya dengan menggunakan LCR meter.

\section{Pembuatan elektroda karbon aktif}

Karbon aktif dikeringkan pada suhu $100^{\circ} \mathrm{C}$ dalam oven selama 1 jam untuk menghilangkan uap air. Setelah itu didinginkan dalam desikator selama 15 menit. Selanjutnya dibuat campuran karbon 
aktif dengan PVDF (polyvinylidene flouride) sebanyak 0,5 gram, dengan perbandingan karbon aktif : PVDF (9:1 (b/b)). Kemudian campuran tersebut ditambahkan larutan NMP (pyrrolidinone) hingga membentuk gel, sambil diaduk selama 15 menit. Setelah itu gel yang terbentuk tersebut dioles diatas permukaan stainless steel 100 mesh, dan dikeringkan di dalam oven pada suhu $100{ }^{\circ} \mathrm{C}$ selama \pm 24 jam.

5. Pembuatan superkapasitor

Dua elektroda karbon aktif ditimbang. Selanjutnya masing-masing elektroda tersebut beserta separator dibasahi dengan larutan elektrolit $\mathrm{H}_{2} \mathrm{SO}_{4} 1 \mathrm{M}$. Selanjutnya dua buah elektroda karbon aktif dan separator yang telah dibasahi $\mathrm{H}_{2} \mathrm{SO}_{4}$ disusun, dimana separator berada di antara kedua elektroda dan ketiga susunan tersebut dimampatkan dengan menggunakan plastik akrilik dan sekrup.

\section{Analisis Data}

Bubuk karbon aktif yang dihasilkan dari proses aktivasi dianalisis menggunakan SEM dan XRD dan Siklik Voltametri. Analisis SEM dilakukan dengan tujuan untuk memeriksa morfologi permukaan sampel, untuk analisis XRD dilakukan untuk mengidentifikasi derajat kristalinitas dan kemurnian dengan melihat spektrum difraksinya, sedangkan siklik voltametri digunakan untuk menghitung nilai kapasitansi spesifik superkapasitor.

\section{HASIL DAN PEMBAHASAN}

\section{Daya jerap iodin dan konduktivitas}

Uji daya jerap iodin dilakukan untuk mengukur tingkat serapan pori yang ukurannya relatif kecil (mikropori). Hasil pengujian daya jerap iodin menunjukkan bahwa daya jerap iodin karbon aktif bambu dengan steam $25 \mathrm{~mL} / \mathrm{bar}$ memiliki nilai yang lebih tinggi yaitu $851,29 \mathrm{mg} / \mathrm{g}$ dibandingkan bambu dengan steam $50 \mathrm{~mL} / \mathrm{bar}$ yaitu $839,01 \mathrm{~mL} / \mathrm{bar}$ (Tabel 1). Hal ini disebabkan karena dengan penambahan steam menyebabkan sejumlah pori dalam karbon aktif menjadi lebih besar, sehingga nilai uji daya jerap iodin untuk karbon aktif bambu dengan steam $25 \mathrm{~mL} / \mathrm{bar}$ relatif lebih kecil dibandingkan dengan steam $50 \mathrm{~mL} / \mathrm{bar}$.
Ketika dibandingkan dengan kontrol (arang tanpa perlakuan penambahan $\mathrm{KOH}$ dan steam) didapatkan bahwa arang yang telah diaktivasi dengan $\mathrm{KOH}$ dan steam 25 $\mathrm{mL} / \mathrm{bar}$, menunjukkan nilai daya jerap iodin yang cenderung lebih besar. Hal ini disebabkan dengan meningkatnya rasio penambahan $\mathrm{KOH}$ dapat menyebabkan peningkatan porositas (Aripin et al. 2010; Babel dan Jurewicz 2004 ; Kierzek et al. 2004).

Hasil pengukuran konduktivitas menunjukkan bahwa nilai konduktivitas dari karbon aktif cenderung makin besar seiring dengan peningkatan steam yaitu sebesar $1521,05 \mathrm{~S} / \mathrm{m}$ untuk karbon aktif bambu dengan steam $25 \mathrm{~mL} / \mathrm{bar}$ dan 1530,83 S/m untuk karbon aktif bambu dengan steam 50 $\mathrm{mL} / \mathrm{bar}$. Hal ini dapat disebabkan oleh berkurangnya komponen-komponen pengotor seperti kadar air, komponen volatile dan mineral sehingga menyebabkan konduktivitas listrik meningkat pada karbon aktif bambu dengan steam $50 \mathrm{~mL} / \mathrm{bar}$. Berdasarkan teori, nilai konduktivitas yang diperoleh ini mendekati nilai konduktivitas grafit yaitu sebesar $3400 \mathrm{~S} / \mathrm{m}$. Sehingga karbon aktif dari bambu yang dihasilkan ini merupakan bahan konduktor.

\section{Morfologi karbon aktif}

Morfologi karbon aktif bambu dengan steam $25 \mathrm{~mL} / \mathrm{bar}$ dan steam 50 $\mathrm{mL} / \mathrm{bar}$, dapat diamati dengan sistem Scanning Electron Microscopy (SEM). SEM dapat memberikan gambaran mendetail mengenai morfologi permukaan, yaitu spesifik pada partikel karbon dan pori pada karbon aktif. Gambar 1 menunjukkan hasil SEM pada karbon aktif bambu dengan perlakuan steam $25 \mathrm{~mL} / \mathrm{bar}$ dan $50 \mathrm{~mL} / \mathrm{bar}$ dengan perbesaran hingga 1000 kali. Perlakuan aktivasi mengakibatkan terbentuknya pori pada permukaan karbon aktif bambu. Perlakuan steam $25 \mathrm{~mL} / \mathrm{bar}$ dan $50 \mathrm{~mL} / \mathrm{bar}$ pada proses aktivasi sampel karbon aktif menyebabkan terbentuknya perbedaan struktur pori pada permukaan karbon aktif. 
Tabel 1. Hasil uji daya jerap iodin dan konduktivitas

\begin{tabular}{ccc}
\hline $\begin{array}{c}\text { Sampel (Sample) } \\
\text { (mL/bar) }\end{array}$ & $\begin{array}{c}\text { Uji Daya Jerap Iodin } \\
\text { (Iodine Absorption Test) }(\mathrm{mg} / \mathrm{g})\end{array}$ & $\begin{array}{c}\text { Konduktivitas } \\
\text { (Conductivity) (S/m) }\end{array}$ \\
\hline Arang Bambu (Kontrol) & 699,22 & 43,63 \\
Bambu dengan steam 25 & 851,29 & 1521,05 \\
Bambu dengan steam 50 & 839,01 & 1530,83 \\
\hline
\end{tabular}

Tabel 2. Tinggi (lc), lebar (la), jarak antar lapisan (d) dan jumlah (n) lapisan aromatik dari karbon aktif bambu

\begin{tabular}{lcccc}
\hline Sampel (Sample) & $\mathrm{d}(\mathrm{nm})$ & $\mathrm{Lc}(\mathrm{nm})$ & $\mathrm{La}(\mathrm{nm})$ & $\mathrm{N}$ \\
\hline Kontrol & 0,371 & 8,411 & 34,130 & 22,671 \\
\hline Steam 25 & 0,371 & 3,561 & 54,362 & 9,598 \\
\hline Steam 50 & 0,371 & 2,753 & 104,82 & 7,420 \\
\hline
\end{tabular}

Dari Gambar 1 tampak bahwa struktur pori pada permukaan karbon aktif bambu steam $50 \mathrm{~mL} / \mathrm{bar}$ memiliki struktur pori dengan distribusi yang lebih seragam, teratur dan smooth juga cenderung memiliki ukuran pori yang lebih besar dibandingkan arang bambu dengan steam $25 \mathrm{~mL} / \mathrm{bar}$. Hal ini diduga dapat disebabkan karena perlakuan steam yang lebih besar hingga 2 kali lipat sehingga dapat menyebabkan terbentuknya ukuran pori yang lebih besar dan distribusi yang lebih merata.

Gambar 2 menunjukkan pola difraksi sinar-X (XRD) karbon aktif bambu. Pola difraksi yang ditunjukkan melalui difraktogram XRD pada Gambar 2, mengindikasikan bahwa sampel karbon aktif yang digunakan dalam penelitian ini berbentuk grafit, amorf, dan tersusun dari atom-atom karbon. Hal tersebut sejalan dengan hasil penelitian yang dilakukan oleh Pari et al. (2004) dengan menggunakan sampel karbon aktif dari serbuk sengon. Setelah diketahui bentuk dan struktur sampel karbon aktif dengan mengidentifikasi pola difraksinya, maka dapat ditelusuri lebih lanjut mengenai tinggi lapisan (Lc), lebar lapisan (La), jumlah lapisan $(\mathrm{N})$ dan jarak antar lapisan (d) dari sampel karbon aktif tersebut, yang dirangkum pada Tabel 2.

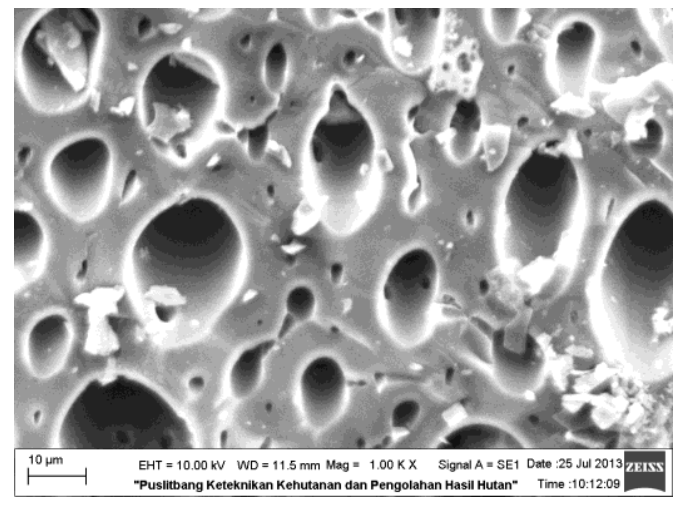

a. Bambu Steam 25

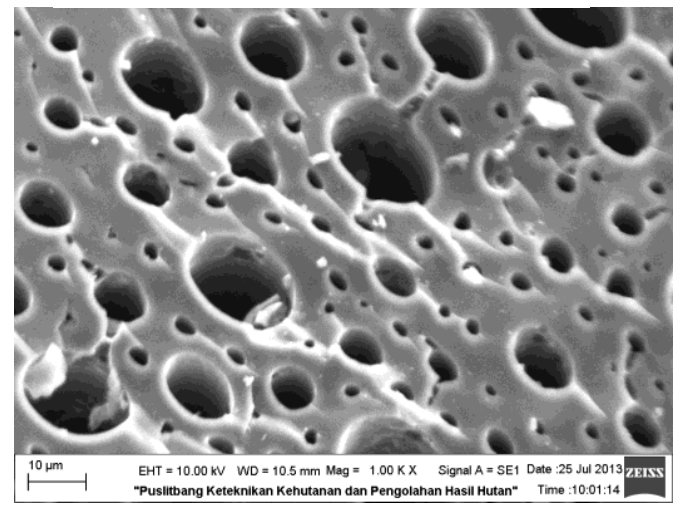

b. Bambu Steam 50

Gambar 1. Citra sem karbon aktif (a) bambu dengan steam 25 dan (b) bambu dengan steam 50 Struktur karbon aktif

Perlakuan steam $(25 \mathrm{~mL} / \mathrm{bar}$ dan 50 $\mathrm{mL} /$ bar) menyebabkan tinggi lapisan (Lc) antar susunan aromatik pada sampel bambu 
cenderung semakin menurun . Hal ini menggambarkan ikatan atom antar karbon menyempit sehingga memperpendek jarak atom antar karbon yang berakibat memperkecil nilai Lc. Begitu juga dengan jumlah lapisan aromatik $(\mathrm{N})$ yang cenderung semakin kecil dengan meningkatnya perlakuan steam, sementara jarak antar lapisan aromatik (d) relatif tetap. Namun, lebar lapisan (La) mengalami peningkatan dengan meningkatnya perlakuan steam.

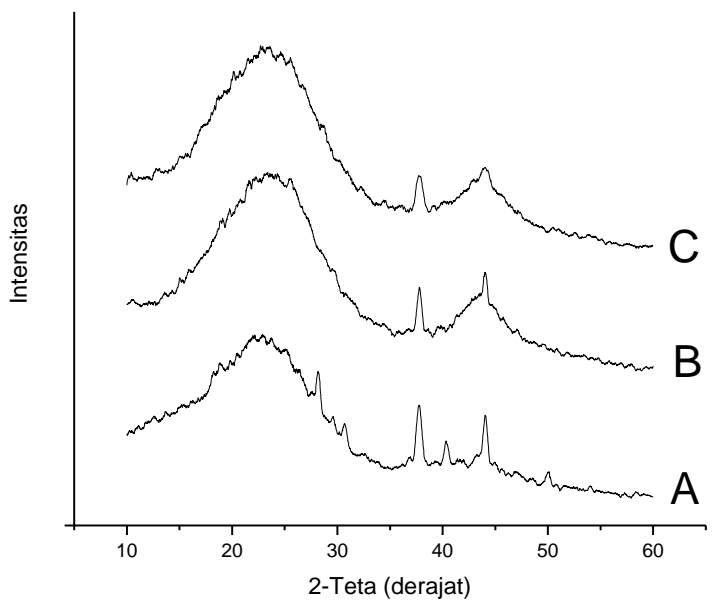

Gambar 2. Difraktogram XRD karbon aktif bambu (a) bambu kontrol; (b) bambu steam 25; (c) bambu steam 50

\section{Kapasitansi spesifik}

Variasi laju scan untuk masing-masing sampel dilakukan untuk mendapatkan nilai kapasitansi tertinggi. Berdasarkan hasil pengukuran untuk masing-masing sampel diperoleh hasil seperti terlihat pada Gambar 3. Hasil pengukuran dengan metode siklik voltametri menunjukkan kurva yang hampir menyerupai empat persegi panjang. Hal ini sesuai dengan hasil yang dikemukakan oleh $\mathrm{Ra}$ et al. (2009) yang menyatakan bahwa bentuk kurva untuk superkapasitor yang berbahan dasar karbon adalah berupa empat persegi panjang.
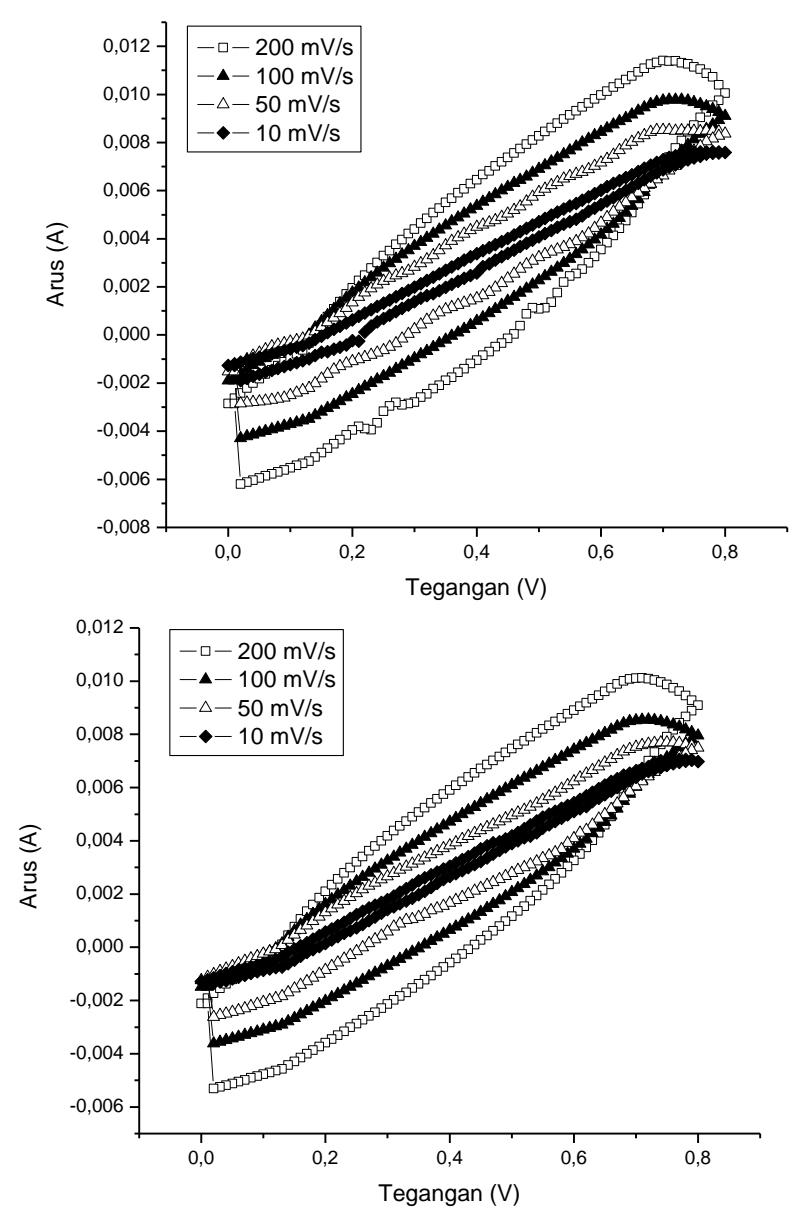

Gambar 3. Variasi laju scan superkapasitor berbasis bambu dengan variasi steam

Hasil variasi laju scan pada masingmasing sampel (steam 25 dan 50) menunjukkan bahwa semakin rendah nilai laju scan luas daerah yang ditunjukkan semakin kecil, dimana luas daerah yang terkecil yaitu pada laju scan $10 \mathrm{mV} / \mathrm{s}$. Hal ini karena arus yang dihasilkan pada laju scan 10 $\mathrm{mV} / \mathrm{s}$ lebih rendah dibandingkan dengan laju scan $50 \mathrm{mV} / \mathrm{s}, 100 \mathrm{mV} / \mathrm{s}$, dan $200 \mathrm{mV} / \mathrm{s}$.

Tingkat kemiringan kurva pada Gambar 2 menunjukkan resistansi internal pada tiap laju scan, dimana tingkat kemiringan yang tertinggi dapat dilihat pada laju scan 200 $\mathrm{mV} / \mathrm{s}$ yang berarti bahwa resistansi internal tertinggi yaitu pada laju scan $200 \mathrm{mV} / \mathrm{s}$. Hal ini menyebabkan resistansi ohmik untuk pergerakan ion dalam elektrolit semakin besar, sehingga pembentukan lapisan ganda antara elektroda dan ion elektrolit menjadi terbatas yang menyebabkan nilai kapasitansi semakin kecil (Liu et al. 2005). Kemiringan 
kurva siklik voltametri yang terendah yaitu pada laju scan $10 \mathrm{mV} / \mathrm{s}$ yang berarti resistansi internal terendah terdapat pada laju scan 10 $\mathrm{mV} / \mathrm{s}$ untuk masing-masing sampel. Hal ini menunjukkan kemampuan paling tinggi superkapasitor dalam menyimpan muatan (Yang et al. 2005; Xing et al. 2006). Hasil perhitungan nilai kapasitansi untuk masingmasing sampel pada variasi laju scan dapat dilihat pada Gambar 3 .

Berdasarkan Gambar 4, tampak bahwa nilai kapasitansi spesifik yang dimiliki oleh superkapasitor dengan elektroda bambu pada steam $50 \mathrm{~mL} / \mathrm{bar}$ lebih tinggi yaitu sebesar $59,50 \mathrm{~F} / \mathrm{g}$ dibandingkan superkapasitor elektroda bambu dengan steam $25 \mathrm{~mL} / \mathrm{bar}$ yaitu sebesar 57,01 F/g. Tingginya nilai kapasitansi spesifik pada superkapasitor elektroda bambu dengan steam $50 \mathrm{~mL} / \mathrm{bar}$ diduga terkait dengan konduktivitas yang dimilikinya lebih tinggi dibandingkan dengan konduktivitas yang dimiliki oleh elektroda bambu dengan steam $25 \mathrm{~mL} /$ bar (Tabel 1). Selain itu peningkatan steam diduga dapat memperbesar pori karbon aktif baik pada bambu maupun sabut kelapa yang menyebabkan distribusi ion elektrolit yang lebih banyak untuk pembentukan lapisan ganda antara elektroda dan ion sehingga menyebabkan nilai kapasitansi spesifik semakin meningkat (Qu dan Shi 1998; Wang et al. 2005).

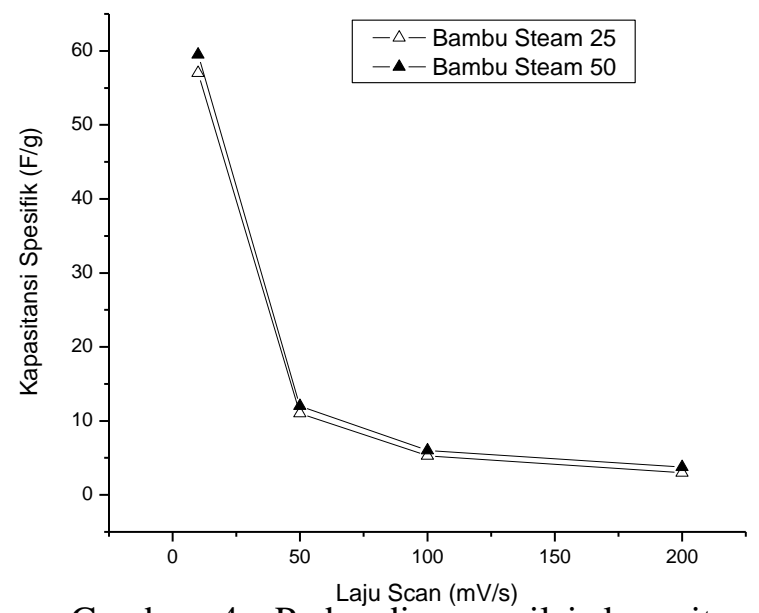

Gambar 4. Perbandingan nilai kapasitansi superkapasitor berbasis bambu dengan variasi steam

\section{KESIMPULAN DAN SARAN}

Karbon aktif berbasis bambu sebagai elektroda superkapasitor berhasil dibuat. Berdasarkan hasil penelitian, nilai kapasitansi spesifik tertinggi dimilik oleh superkapasitor dengan elektroda karbon aktif bambu pada aktivasi steam 50 yaitu 59,50 F/g. Hal ini menunjukkan bahwa karbon aktif berbasis bambu layak untuk dimanfaatkan sebagai bahan baku pembuatan elektroda superkapasitor.

Proses aktivasi arang bambu dengan variasi $\mathrm{KOH}$ dan steam perlu ditingkatkan untuk mendapatkan hasil karbon aktif dengan ukuran pori yang lebih optimal, sehingga dapat menghasilkan elektroda superkapasitor dengan nilai kapasitansi spesifik yang lebih tinggi.

\section{DAFTAR PUSTAKA}

Aripin H, Lestari L, Ismail D, Sabchevski S. 2010. Sago Wasted Based Activated Carbon Film as an Electrode Material for Electric Double Layer Capacitor. The Open Materials Science Journal $2010 ; 4$ : 117-124.

Babel K, Jurewicz K. 2004. KOH Activated Carbon Fabrics as Supercapacitor Material. Journal of Physics and Chemistry of Solids $2004 ; 65: 275$ 280.

Chijuan Hu. 2008. Fluid Coke Derived Activated Carbon as Electrode Material for Electrochemical Double Layer Capacitor [Tesis]. Toronto. Graduate Department of Chemical Engineering and Applied Chemistry, University of Toronto.

Fellman B. 2010. Carbon-Based Electric Double Layer Capacitors for Water Desalination [Tesis]. Department of Mechanical Engineering, Massachusetts Institute of Technology.

Kierzek K, Frackowiak E, Lota E, Grylewicz G, Machnikowski J. 2004. Electrochemical Capacitors Based on Highly Porous Carbon Prepared by $\mathrm{KOH}$ Activation. Electrochemical Acta ; $49: 515-523$.

La Ode Muhammad, Wahid Abdul. 2005. Sensitivitas Analisis Potensi Produksi PembangkitListrik Renewable untuk 
Penyediaan Listrik Indonesia. Strategi Penyediaan Listrik Nasional Dalam Rangka Mengantisipasi Pemanfaatan PLTU Batubara Skala Kecil, PLTN, Dan Energi Terbarukan : Pusat Pengkajian dan Penerapan Teknologi Konversi dan Konservasi Energi- BPPT, hlm 13-22

Liu, H. Y., Wang, K. P., and Teng, H. S. 2005. A simplified preparation of mesoporous

carbon and the examination of the carbon accessibility for electric double layer formation. Carbon 43: 559-566.

Pari G, Sofyan K, Syafii W, Buchari. 2004. Pengaruh Lama Aktivasi Terhadap Struktur Kimia Dan Mutu Arang Aktif Serbuk Gergaji Sengon. Jurnal Penelitian Hasil Hutan 2004 ; 8: 8-16. Pusat Penelitian dan Pengembangan Hasil Hutan, Bogor

Qu, D. Y., and Shi, H. 1998. Studies of activated carbons used in doublelayer capacitors. Journal of Power Sources 74; 99-107.

Ra.E .J., E. Raymundo-pinero, Y.H. Lee, F. Beguin. 2009. High power supercapacitors using

polyacryylonitrile carbon nano fiber paper. Carbon 47: 2984-2992.
Wang, X. F., Ruan, D. B., Wang, D. Z., and Liang, J. 2005. Hybrid electrochemical

supercapacitors based on polyaniline and activated carbon electrodes. Acta Physico-Chimica Sinica 21; 261-266.

Xing, W., Qiao, S. Z., Ding, R. G., Li, F., Lu, G. Q., Yan, Z. F., et al. 2006. Superior

electric double layer capacitors using ordered mesoporous carbons. Carbon 44; 216-224.

Yang, C. C., Hsu, S. T., and Chien, W. C. 2005. All solid-state electric doublelayer

capacitors based on alkaline polyvinyl alcohol polymer electrolytes. Journal of Power Sources 152; 303-310.

Yueming Li, van Zijll M, Chiang S, Pan N. KOH Modified Graphene Nanosheets for Supercapacitor Electrodes. Journal of Power Sources $2011 ; 196$ : 6003-6006.

Zuleta M, Bjornbom P, Lundblad A. 2005. Effects of Pore Surface Oxidation on Electrochemical and Mass-Transport Properties of Nanoporous Carbon. Journal of The Electrochemical Society ; 152 : 270-276. 